\title{
Impactos ambientales generados por la actividad deportiva, recreativa y turística en alta montaña. Análisis de la cordillera de la Región Metropolitana de Santiago, Chile \\ Environmental impact generated by sports, recreation, and tourism activities in high mountain. Analysis of the mountain range of the Metropolitan Region of Santiago, Chile
}

\author{
Pablo Rebolledo Dujisin
}

Universidad Andres Bello (Chile)

\begin{abstract}
Resumen. El objetivo del estudio consiste en aportar el conocimiento de los efectos generados por la actividad deportiva y la recreación en alta montaña, para fortalecer la gestión y la disminución de los impactos indeseables. El método ha consistido en la aplicación de una herramienta cualitativa y una cuantitativa: una encuesta a los actores relevantes dentro del mundo actividades recreativas de alta montaña y una adaptación de la Matriz de Leopold en senderos, campamentos y cumbres de dos sectores de práctica del deporte de alta montaña en la zona central de Chile; la revisión bibliográfica permite comprender, por otra parte, el fenómeno y destacar las iniciativas de las federaciones internacionales de actividades deportivas de montaña para la gestión ambiental. Llama la atención, como conclusión de la encuesta, la percepción del deporte de alta montaña como una actividad inocua que genera impactos despreciables y, por otra parte, destaca en los resultados de la Matriz de Leopold la concentración de desperdicios, los efectos de las tiendas de campaña y los baños improvisados, afectando principalmente a las fuentes de agua y al suelo. Lo que conlleva una situación donde los tomadores de decisión no son conscientes de los efectos y, por lo tanto, no están tomando las medidas adecuadas para su control.
\end{abstract}

Palabras clave: actividades deportivas, alta montaña, impactos ambientales, buenas prácticas, conservación, espacios naturales.

\begin{abstract}
The objective of the study is to provide knowledge about the effects generated by sports and recreation in high altitude mountains, to strengthen their management and decrease their undesirable impacts. The method consisted in the application of qualitative and quantitative tools: a survey to stakeholders, and an adaptation of the Leopold Matrix on trails, camps and summits in two areas for high altitude sport in the central region of Chile; on the other hand, bibliographic review allows to understand this phenomenon, and highlight the initiatives of international federations of mountain sports for better environmental management. As a conclusion of the survey, a surprising finding is that high mountain sports are perceived as innocuous activities that generate negligible impacts; on the other hand, concentration of waste, and effects of tents and improvised toilets stand out as main results from the Leopold Matrix, mainly affecting water sources and soil. This demonstrates that decision makers are not aware of the effects of mountain sports and, therefore, they are not taking appropriate measures to control them.
\end{abstract}

Keywords: mountain sports activities, environmental impacts, better practices, conservation, natural spaces.

\section{Introducción}

Es innegable la persistencia de la cordillera andina en todo el Cono Sur y, con esto, es de suponer que un buen número de actividades deportivas y turísticas que se desarrollan en Chile se practiquen es estos escenarios (Rebolledo \& Fica, 2010), entre ellas la escalada de alta montaña, conocida localmente como «andinismo» y todas sus expresiones.

La literatura indica que la práctica de actividades deportivo-recreativas que se basan en la naturaleza muestran un notable aumento (Morilla, Rebollo, Baena, Miranda, \& Martínez, 2013) ya sea por la aparición de nuevos deportes o por la simple atracción de más personas (López, y otros, 2019) que vienen motivadas por la ruptura con la cotidianeidad y la rutina (Guillén \& Peñarrubia, 2013). En zonas de montaña está en aumento, tanto en volumen de visitas como en tipología de actividades (Mutana \& Mukwada, 2018); en Chile, al igual que en muchos países de la Región, no existen datos fidedignos que permitan diagnosticar el desarrollo, aporte ni tendencias del deporte o turismo de montaña (Rebolledo \& Fica, 2010) por lo que es difícil establecer las tendencias actuales o el desarrollo de actividades específicas en territorios determinados, sin embargo y a modo aproximativo, podemos indicar que las visitas a áreas silvestres protegidas del Estado, en los últimos 5

Fecha recepción: 04-12-18. Fecha de aceptación: 07-06-19

Pablo Rebolledo Dujisin

pablo.rebolledo@unab.cl años, tienen un crecimiento promedio anual de más del 7\%, pasando de 2 millones de visitantes en 2012 a más de 3 millones en 2017 (CONAF, 2018).

En otro orden de cosas, en el año 2009 aparece en la revista «Retos: nuevas tendencias en educación física, deporte y recreación» un artículo planteando una problemática no resuelta; Farías \& Sallent (2009) expresan la importancia de comprender que, cualquier actividad humana, en particular aquellas en espacios sensibles, genera impactos ambientales, de poca magnitud, pero en sectores normalmente prístinos que actúan como escenario obligado de las actividades físicas al aire libre.

De este modo, en el presente estudio se abordará la actividad físico-deportiva de alta montaña, la cual, tanto en la normativa chilena de calidad turística, como en la comprensión por parte de la Federación de Andinismo de Chile (FEACH) se define como sigue:

Alta Montaña Actividad cuyo fin es la ascensión y descenso de montañas; paredes de roca, nieve, hielo o mixtas; cascadas de hielo; glaciares; terrenos nevados; terrenos mixtos y similares de una escala de dificultad, compromiso o altitud que requiere para ello, toda la amplia gama de técnicas del montañismo, la escalada y el esquí; también incluye cualquier actividad que requiere de aclimatación (INN, 2005, p.1).

La práctica de esta actividad requiere de entrenamiento y técnica, pues es reservada para «expertos». En ese sentido se espera que el practicante tenga formación en alguna escuela especializada y participe de expediciones que van desde 3 a 30 días por lo general. 
El campismo es casi obligatorio, pero en muchas ocasiones se opta por el vivac pues esto economiza el transporte de peso extra.

Importante de recalcar que la práctica del deporte de alta montaña, tanto deportistas como animales de carga, invade espacios naturales con suelos que permanecen en permafrost, praderas y ciénagas, causando un problema ambiental serio asociado a los desechos sanitarios y la contaminación del agua, a la acumulación de basura, la compactación de suelos en sectores de campamento y el impacto sobre la fauna escasa (Barros \& Pickering, 2015) afectando ambientes muy sensibles, pues estos escenarios son fuentes de minerales, de agua y, en general de vida, siendo, a la vez, uno de los ecosistemas más frágiles y sensibles de la tierra.

Tal como plantean Hammitt y Cole (1998) en (Farías \& Sallent, 2009) existen variadas dimensiones en las cuales se puede estudiar los impactos generados por la actividad deportiva en espacios naturales, sin embargo, a nivel de características intrínsecas de la actividad deportiva y/o turística de alta montaña, podemos esperar, al menos, impactos de los siguientes tipos: aparición y permanencia de desechos humanos; aparición y permanencia de microbasurales; fracción de glaciares; contaminación del agua (química o bacterial); destrucción del patrimonio cultural; destrucción de humedales de altura; merma de la flora y fauna local; afectación de comportamiento y patrones de la fauna (Barros, Monz, \& Pickering, 2015).

La temática planteada requiere de un estudio acabado que permita describir el fenómeno relacionado con los impactos ambientales generados por deportistas y turistas en zonas de montaña, puesto que, a pesar de la popularidad de la actividad recreativa y el valor ecosistémico de las montañas, existen limitadas investigaciones, con excepción de algunos trabajos presentados por Luís Cánepa y Matilde Encabo (Cánepa \& Encabo, 2013), que permitan conducir de manera adecuada el desarrollo de actividades recreativas en zonas de montaña (Barros, Monz, \& Pickering, 2015) lo que constituye en el problema central del presente trabajo.

La intención de este documento es, entonces, aportar a la misma línea de conocimiento desde la perspectiva del uso de los espacios montañosos para la actividad deportiva y turística de la alta montaña, tomando como caso de estudio la zona central de Chile en dos lugares populares de esta práctica, el Cerro El Plomo (5.424 msnm) y el Volcán San José (5.856 msnm); el problema planteado es, entonces, el escaso conocimiento respecto de los impactos indeseables y, por lo tanto, las exiguas medidas de control que se han implementado, intentándose aportar tanto al conocimiento como al control de los impactos para dar lugar a los beneficios sociales propios de la actividad deportiva y de la promoción de estilos de vida activos,

\section{Impactos Ambientales de la Actividad Deportivo-Re- creativa}

Según la ley vigente en Chile un Impacto Ambiental es la:

Alteración del medio ambiente, provocada directa o indirectamente por un proyecto o actividad en un área determinada» (Ley 19.300, 1994).

$\mathrm{O}$, como también lo define la normativa nacional de turismo aventura:
Consecuencias, alteración, modificación o cambio en el ambiente o en alguno de sus componentes de cierta magnitud y complejidad, originado o producido por los efectos de la acción o actividad humana» (INN, 2005, p.3).

Y, como toda actividad antrópica, aquellas pertenecientes al ámbito del deporte y la recreación, evidentemente presentan algunos impactos sobre el medio ambiente. Es importante recordar que este estudio abordará únicamente los impactos generados directamente por la actividad deportivorecreativa o turística, puesto que no puede hacerse cargo de otros agentes como el sobrepastoreo, la actividad minera, el cambio climático o la polución.

Dicho lo anterior, se entiende que todas las actividades deportivo-recreativas o turísticas pueden producir impactos en el territorio; en el caso extremo, nada infrecuente, la presión antrópica ejercida determinado medio puede acabar con sus propios atractivos naturales; pudiendo terminar en una destrucción de las aptitudes territoriales iniciales (Callizo, 1991) generando, en el tiempo, grandes espacios acondicionados para la recreación, pero abandonados por los usuarios.

Las actividades de manejo permiten influir en el tiempo y la localización del impacto ambiental, sin embargo, la capacidad de los administradores para minimizarlo puede verse disminuida si existen limitaciones en la comprensión de aspectos fundamentales de éste, como la dinámica del proceso y el rango total de acción (Stankey \& Manning, 1986), elementos que hoy, en Chile, no son considerandos en los sectores de práctica del deporte de alta montaña.

\section{Impactos Sobre el Espacio Montañoso}

La preocupación y estudio acerca de los impactos ambientales generados por los visitantes en los espacios naturales comenzó en los años '60 junto con el incremento de la demanda por instalaciones en espacios al aire libre (Gill \& Williams, 1994). El excesivo número de visitantes en los espacios montañosos, trae consigo la degradación ambiental de estos territorios; la superación de la capacidad de carga, el uso de las fuentes de agua y otros, se da en áreas relativamente pequeñas en muchos macizos montañosos, siendo éstos, junto con los impactos de otras industrias, algunos de los otros factores que afectan a los ambientes de montaña en conjunto (Barros \& Pickering, 2015).

Este uso masivo parece ser mucho más significativo en las áreas asociadas a las montañas que reciben mayor número de deportistas y visitantes, así, campamentos, caminos y quebradas deben ser manejados mediante la adopción de técnicas de buenas prácticas ambientales (UIAA, 1997) con una comprensión cercana de la calidad esperada de las experiencias recreativas, sin dejar de lado el hecho de que los entornos de montaña son frágiles (Mutana \& Mukwada, 2018).

Con paisajes y ecosistemas especialmente frágiles y susceptibles al cambio y la degradación, las montañas deben ser tratadas con particular cuidado, las actividades recreativas a menudo conllevan el desarrollo y el uso intensivo de pistas, senderos y pendientes deportivas por parte de vehículos, transporte con o sin motor y caminantes (UNEP, 2007), sin embargo, la extrema estacionalidad, la falta de disponibilidad de infraestructura, la planificación ineficiente y la interferen- 
cia con estos frágiles ecosistemas, en particular en los países en desarrollo (Sundriyal, Shridhar, Madhwal, Pandey, \& Sharma, 2018) han llevado a la actividad recreativa de alta montaña a ser, en muchas localidades, un elemento indeseable.

La actividad de montaña suele concentrar las visitas en pequeñas áreas: campamentos y cumbres (sitios puntuales), senderos, huellas y rutas (sitios lineales), etc. Los efectos medioambientales negativos de las actividades recreativas gestionadas deficientemente pueden ser el aumento significativo del ruido, la reducción de la vegetación y la erosión del suelo, la eliminación de hábitats escasos, la modificación de paisajes y flujos de agua esenciales, la contaminación del agua y el aire y el cambio del comportamiento y la ubicación de la vida silvestre.

Sin embargo, los impactos no solamente ocurren sobre el medio ambiente; las comunidades montañosas también pueden ser susceptibles a los impactos y cambios provocados por las actividades turístico-recreativas, entre ellos destacan: molestias por altos niveles y concentración de ruido y actividad por parte de los visitantes, así como la reducción de recursos escasos compartidos como leña, pescado y agua dulce. Además, la exposición y adopción de tradiciones, estilos de vida y productos foráneos pueden suponer una amenaza a la cultura, tradiciones, conocimientos y medios de subsistencia de las poblaciones montañeras, particularmente cuando se trata de comunidades remotas e indígenas (UNEP, 2007). Así como también, cuando se generan trabajos en espacios pobremente gestionados, las condiciones laborales pueden ser deficientes, y los ingresos pueden salir fácilmente de las economías locales para acabar en empresas foráneas.

Con esta información y con los años que se lleva poniendo este tema en el tapete, es difícil pensar por qué no se toman las medidas necesarias para administrar, gestionar y, en algunos casos, recuperar los valores naturales de estos espacios. Bien, la generación de divisas a través del turismo y el deporte de montaña han crecido especialmente a partir de las últimas décadas y, muy probablemente, este es el motivo principal de que las autoridades correspondientes parezcan poco dispuestos a aceptar sus responsabilidades con respecto al medio y a su gestión. No parecen aceptar el hecho de que la actividad humana en la montaña tiene un claro impacto sobre ella. Los intereses económicos prevalecen y el miedo a perder mercado les previene contra cambios que podrían alterar de forma importante la naturaleza actual del negocio. Lamentablemente, los intereses económicos, como suele ocurrir en nuestro país, han ocultado los impactos negativos sobre otros aspectos del medio ambiente (Saz \& Carús, 2008).

Se propone, entonces, como objetivo central analizar la problemática generada por la actividad deportiva y/o turística en territorios montañosos y sus impactos ambientales tomando como caso de estudio la actividad de Alta Montaña en la zona central de Chile.

\section{Zona de Estudio}

Más de un cuarto de la superficie total de la tierra está cubierta por zonas montañosas o altiplanos, todos los continentes tienen cadenas montañosas originando una amplia gama de climas, desde las costas húmedas hasta los secos desiertos, siendo el escenario de una amplia colección de ecosistemas; todas las montañas presentan gran diversidad biológica y ecosistemas muy frágiles (Global Environmental Facility, 2002).

Cerca del $40 \%$ de la población humana depende directa o indirectamente de los ecosistemas montañosos, esto porque los servicios ambientales de la montaña incluyen la protección de laderas, la conservación de recursos hídricos, la producción agrícola y otros como el ser escenario del desarrollo de actividades productivas, energéticas, de transporte, etc. (Körner, 2000). Es así como la protección de los suelos es la clave para el uso y gestión sustentable de las tierras de montañas, en específico la protección de la vegetación diversa para proteger los suelos y sustentar los servicios ambientales en estos sistemas (Körner, 2000).

Gracias a sus dos cadenas montañosas principales, la de Los Andes y la de La Costa y la serie de pequeños sistemas cordilleranos que se encuentran en el territorio chileno, gran parte del espacio nacional se encuentra asociado a zonas de montaña, alta montaña, altiplanos o campos de hielo, algunos autores plantean que un 64\% del territorio está en estas zonas (FAO, 2012) y otros llegan a una estimación de cerca del 80\% (Gabriel, Jordan, Millar, Pérez, \& Urtubia, 2006). Esto no sorprende si se hace el análisis del territorio nacional, donde se extiende la cordillera de La Costa, por cerca de 3.000 kilómetros de norte a sur, respaldada por la cordillera de Los Andes con un largo de 10.000 kilómetros, desde el Mar del Caribe hasta el Cabo de Hornos, de éstos, 4.200 kilómetros están asociados al territorio chileno (Börgel, Romero, \& Vio, 1983).

Los Andes del sur, desde el desierto de Atacama hasta el fin del Cono Sur, es una zona más temperada y estacional, el clima se va enfriando según se avanza en latitud hasta que la Patagonia presenta un clima polar y un ambiente con abundancia de glaciares (Funnel \& Parish, 2001). Esta transición entre zonas ambientales con altitudes y latitudes se reflejan en la adaptación de las comunidades locales, la agricultura, domesticación de animales y organización social son efectos de los diferentes ecosistemas asociados a Los Andes.

Dentro de la gran cantidad de montañas en estas cordilleras, se utilizaron como área de estudio dos de ellas, el Cerro el Plomo (5.424 msnm), ubicado en la comuna de Lo Barnechea y el Volcán San José (5.856 msnm) ubicado en la comuna de San José, ambas pertenecientes a la Región Metropolitana de Chile, las cuales serán contextualizadas en el apartado 2.

\section{Material y Método}

Se trata de un estudio descriptivo que se sitúa sobre bases de conocimiento proveniente de bibliografía internacional y nacional y de la implementación de una herramienta de recogida de información in-situ, desarrollando, finalmente, una investigación aplicada con métodos numéricos, donde se busca aportar con información para poder llegar a establecer caminos que conduzcan al esclarecimiento de relaciones causales entre la actividad física de alta montaña y los impactos ambientales en el territorio.

Es importante mencionar que, para efectos de este estu- 
dio no se diferenció el uso antrópico de alta montaña entre turismo, deporte o recreación, utilizándose de manera indistinta cualquiera de los tres conceptos; importante de destacar puesto que se están evaluando impactos de la actividad física, independiente de la motivación que tenga la persona para acceder a los lugares estudiados, que, por lo demás, para el caso, están profundamente interrelacionados.

Por otra parte, se insiste en que el estudio se centró en dos montañas de la zona central de Chile, estudiándose los sectores de campamento y cumbre (sitio de visita puntual) y los senderos, huellas y caminos pedestres (sitios de visita puntual) del Cerro el Plomo y Volcán San José en la zona central de Chile:

\section{Cerro El Plomo}

Ruta «Normal»

Refugio Federación (4100msnm) Lat = -33.26221, Lon = 70.23073

Cumbre(5424msnm)Lat: -33.23692, Lon: -70.21392

\author{
Volcán San José \\ Ruta «Normal» \\ Campamento 1: refugio Plantat $(3130 \mathrm{msnm})$ Lat = - \\ 33.80124, Lon $=-69.96647$ \\ Campamento 2: C2 (+/-4800msnm) Lat = -33.77499, Lon = \\ $-69.92868$ \\ Cumbre $(5856 \mathrm{msnm})$ Lat $=-33.78929$, Lon $=-69.90184$
}

En este sector son muy evidentes los rasgos del plegamiento estructural y de volcanismo, mostrando un aspecto aserrado en ambas montañas constituidas, principalmente, por estratos y rocas volcánicas y sedimentarias del Cretácico, Jurásico y Plioceno, las que se encuentran falladas y plegadas (Gutierrez, Larrain, Molina, \& Rivera, 1986), presentando las características de una montaña de relieve joven y una vegetación que disminuye a medida que aumenta la altitud; se estima que en la cordillera de la región, se pueden encontrar unas 600 especies de platas vasculares, de éstas el 90\% son nativas, visualizándose poca intervención antrópica (Teillier, Marticorena, \& Niemeyer, 2011).

Respecto de los aspectos sociales, el sector no presenta poblaciones permanentes debido a sus condiciones ambientales, sin embargo, la forma de vida del arriero, herencia de los primeros «yegüerizos» en la «dehesa del rey» en Santiago, se mantiene como trashumante, desplazando ganado a través de los diferentes pisos vegetacionales de la cordillera; en la zona de Santiago, principalmente a través del subsistema hídrico del río Mapocho Medio Montano y del río Maipo Cordillerano Sur (Olivares, 2002).

En una primera etapa, se diseñó y aplicó una encuesta abierta que permite obtener un sondeo tanto de opinión como de la realidad asociada a la mitigación y gestión de impactos ambientales generados por el turismo y deporte de montaña. Esta encuesta responde a un muestreo intencionado donde las respuestas representan la opinión de quienes las emiten. La encuesta se realizó a un grupo considerado «personajes relevantes» por lo que no se utilizó un método para calcular el tamaño muestral en un periodo de 50 días entre los meses de octubre, noviembre y diciembre de 2017.

Sin embargo, y con el fin de diferenciar resultados, se establecieron algunas preguntas diferenciadas para las empresas turísticas (actores privados) que permiten obtener nuevos datos.

Los encuestados se seleccionaron según el criterio del investigador, aquellos que fuesen más relevantes en su accionar sobre los espacios turísticos montañosos, para el sector público y las empresas turísticas se seleccionaron las dos empresas de turismo de montaña más grandes de Santiago y algunas de tamaño pequeño de forma azarosa.

La segunda etapa, aplicada en terreno, se basó en la aplicación de una adaptación propia de la Matriz de Leopold (Leopold, Clarke, Hanshaw, \& Balsley, 1971), un método de evaluación de impacto ambiental que se utiliza con la finalidad de evaluar costos y beneficios ecológicos, el análisis no produce un conjunto de juicios de valor ordenados en filas y columnas y que busca evaluar y considerar los impactos generados por una acción. Se trata de un método ampliamente utilizado, en particular en proyectos que ingresan al Sistema de Evaluación de Impacto Ambiental de Chile. La matriz requiere, para nutrirse, de una previa identificación de las interacciones existentes entre el medio ambiente y la actividad, es decir, de los impactos ambientales, sin embargo, se redujeron en lo posible todas las filas y columnas que no sean significativas para la actividad deportivo recreativa (García, 2004).

Las Campañas del Volcán San José, desarrolladas en enero y febrero y ambas con cumbre, fueron abordadas por un especialista en turismo, un geógrafo y un biólogo ambiental a través de la ruta normal, con pernoctaciones en el refugio Plantat, el campamento 2 y regreso al Plantat.

Esta adaptación consideró factores ambientales (Tabla 1) y las actividades propias de la alta montaña (Tabla 2), excluyéndose el traslado en vehículo o los andariveles de esquí. A cada cruce de variables se le asignó una Magnitud (valoración del impacto) que va de 1 a 10 con un signo + para aquellos positivos y un - para los negativos, además de una Importancia (relevancia sobre la calidad del medio o extensión territorial), que se califica con la misma escala.

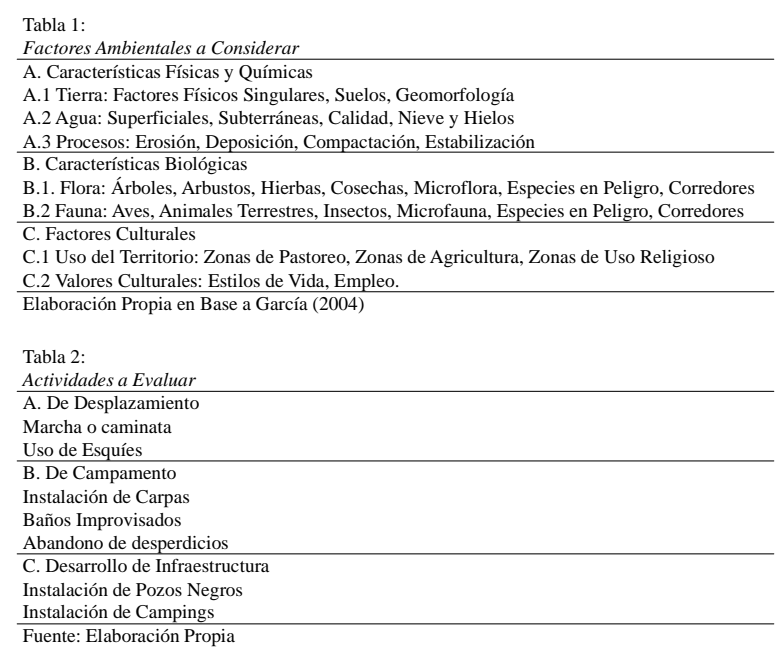

Para su implementación se llevaron a cabo cuatro campañas de terreno, dos para cada una de las montañas en evaluación, con estudios levantados en las temporadas de verano, tanto al principio (diciembre) como al final (marzo) de éste, momentos en que es más fácil observar los impactos 
antrópicos en el territorio, la visita fue acompañada, en cada ocasión, por profesionales con experticias en distintas ciencias ambientales que sirvieron como referente experto en cada elemento a evaluar.

Para el cerro El Plomo se siguió la ruta desde La Parva, a través del portezuelo y laguna de Piuquenes, siguiendo el sendero a Piedra Numerada por aproximadamente 4 horas para pernoctar en las inmediaciones del refugio Federación. La primera campaña de diciembre no permitió el acenso a la cumbre, por lo que solo fueron evaluados los campamentos y senderos; la segunda campaña de enero permitió el ascenso a la cumbre y la evaluación de los otros lugares por parte de un especialista en turismo, un geógrafo, un biólogo ambiental y una arqueóloga. La expedición en total se realizó en 3 días.

Los aspectos únicos de los sistemas montañosos hacen pensar que, en algunos casos podría haber factores ambientales que sean afectados de forma crítica, pero que dentro del medio receptor ese factor no tenga mucha importancia, es decir, sea de magnitud limitada.

Finalmente se debe mencionar que la discusión asociada a la matriz consistirá exclusivamente en los impactos más significativos, es decir aquellos cuyas filas y columnas tengan calificaciones mayores.

Se debe considerar, sin embargo, que el método de aplicación numérica a la matriz, a pesar de ser apoyada con expertos en la materia podría carecer de objetividad pues la calificación entre 1 y 10 está asociada a la percepción del o los evaluadores la cual se puede ver afectada por los efectos de la altitud en el juicio de las personas (Niedermeier, y otros, 2017), la medida tomada para minimizar este efecto fue la selección de profesionales con amplia experiencia en ascenso a la montaña, lo que permite que la persona idenifique su propio nivel de juicio.

\section{Resultados}

Los resultados de los procesos de investigación son comunes a los dos espacios naturales analizados, se encontró homogeneidad tanto en las encuestas como en la aplicación de la Matriz por lo que se presentan como uno solo tanto en este acápite como en la discusión.

\section{Encuestas}

En general se puede apreciar que en todos los encuestados existe al menos una preocupación por la contaminación e impactos ambientales que la actividad recreativa está generando en estos lugares, siendo la acumulación de basura, ya sea de desechos regulares o desechos humanos lo que más parece preocupante, entre ellos destaca la presencia de papel higiénico como el factor considerado más relevante y visible como residuo de la actividad. Por otro lado, y en general, la actividad es considerada inocua, incluyendo la instalación de campamentos de temporada.

Lo anterior es lo más preocupante puesto que al no tener conciencia, aquellos que utilizan y administran estos espacios, acerca de los verdaderos impactos y efectos indeseados ambientales que produce el deporte y turismo de montaña, no se podrán tomar las medidas apropiadas de gestión, miti- gación, reparación y prevención de impactos.

En cuanto al patrimonio cultural también es relevante que, de las empresas encuestadas, sólo una mencionó darle importancia o un tratamiento especial, las demás no lo consideran como un «ítem» dentro de sus productos turísticos a menos que sea demasiado evidente. Lo contrario ocurre con las comunidades locales donde los empresarios aseguran hacer lo posible por integrarlos dentro de los circuitos turísticos ya sea como proveedores o como guías locales, sin embargo, por ejemplo, la Federación de Andinismo de Chile (FEACH) comentó la incorporación de aspectos ambientales en sus cursos básicos dictados a través de la Escuela Nacional de Montaña, pero no incluir aspectos culturales en éstos.

Todo lo anterior muestra un panorama poco alentador, principalmente porque demuestra poco interés y poco conocimiento de la realidad de la actividad, tanto por parte de empresarios turísticos como por parte de las autoridades y otros organismos involucrados en la gestión de espacios montañosos.

El resultado de las encuestas arroja como conclusión que actualmente no se toman medidas relevantes para la gestión de impactos ambientales generadas por las actividades recreativas o turísticas, principalmente se trata de algunos esfuerzos aislados donde los empresarios privados realizan campañas de limpieza de ciertos sectores de uso turístico, sin ser esto una actividad regular ni con seguimiento, por su parte la FEACH en coordinación con empresas o con el Cuerpo de Socorro Andino organizan jornadas de limpieza en los campamentos principales de los dos lugares estudiados.

En cuanto a las autoridades parece ser la creación de mesas de trabajo, de informes y reuniones la única actividad que se realiza en este sentido, olvidando lo principal, que es la aplicación efectiva y real de acciones que puedan aportar a este objetivo, pues, como se ha mencionado anteriormente, la actividad es cada vez más masiva y, por tanto, cada vez sus efectos indeseados serán más difíciles de resolver o restaurar.

El escenario de otras instituciones públicas y privadas sin fines de lucro es similar, al parecer acciones específicas son casi inexistentes, y todo pareciera depender de algunos personajes; éste es el caso, por ejemplo, del Ministerio de Relaciones Exteriores, donde es la persona encuestada llevó a cabo las acciones necesarias para poner en el tapete la «Mesa para las Montañas» que terminó con la creación de un Comité Nacional para las Montañas que incluye el uso del espacio para turismo, deporte y recreación.

Otras instituciones como Ministerio de Medio Ambiente, Fundación Sendero de Chile y Escuela Nacional de Montaña dicen realizar actividades de educación ambiental aportando directamente al desarrollo de habilidades que permitirían, en el futuro, disminuir los impactos ambientales generados por la actividad, lo cual fue verificado mediante la revisión de sus sitios Web.

Finalmente, de los encuestados, tanto público como privados y otras instituciones, todos reconocen a la educación ambiental como la única herramienta eficiente para la gestión de estos espacios; quizás asociado a la poca posibilidad de realizar monitoreo y fiscalizaciones en este sector. 


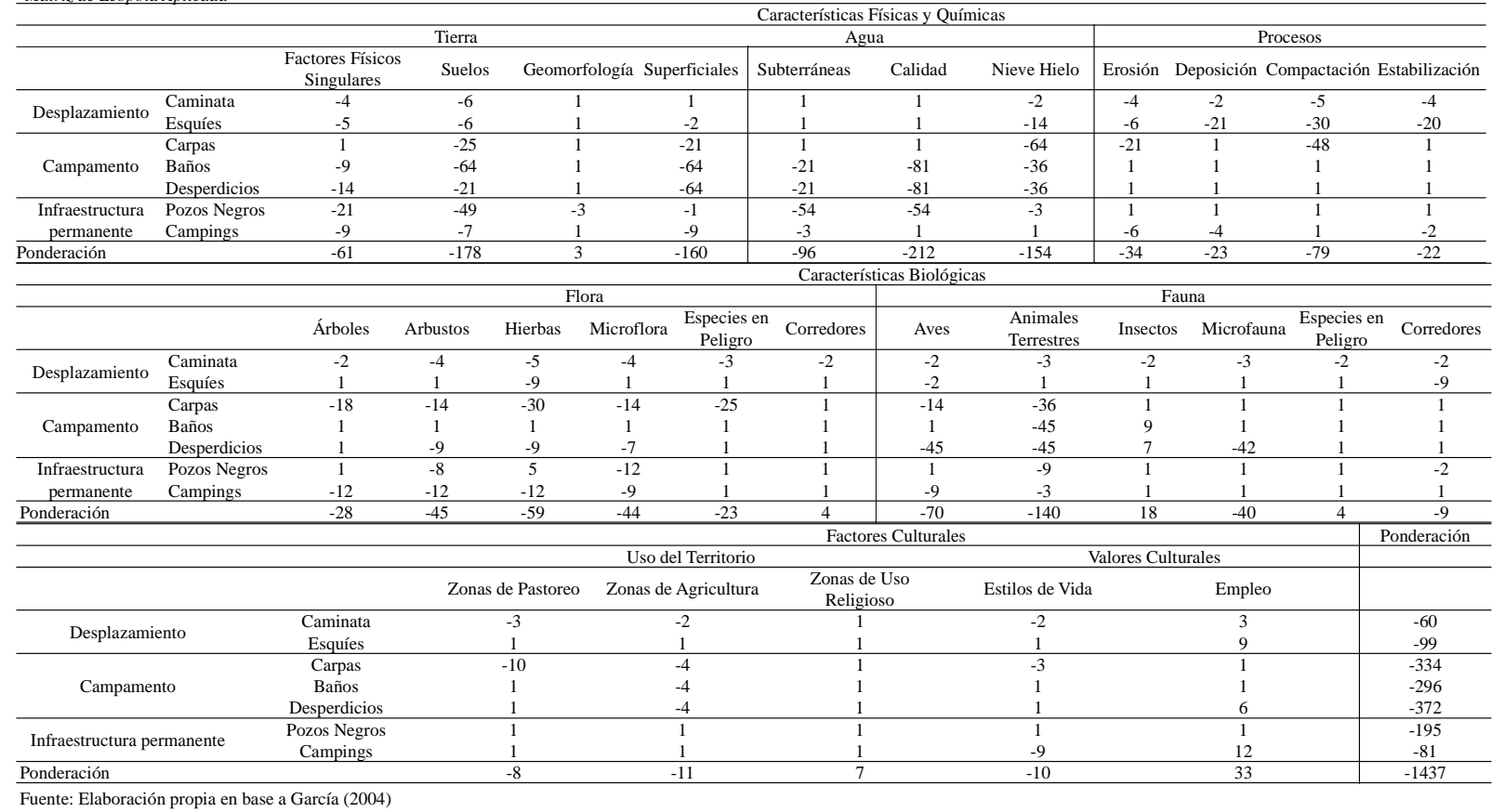

\section{Matriz de Leopold}

Los resultados de la aplicación de la Matriz de Leopold se pueden ver en la Tabla 3 y sus principales hallazgos son los que se expresan a continuación:

Lógica Horizontal: Se hacen evidentes los impactos apreciables por la presencia de desperdicios en superficie (o abandono de desperdicios) (-372); a pesar de que por lo general se considera un elemento menor, su abandono es un proceso que, es irreversible por sí solo y requiere de una intervención antrópica intencionada para mejorarse, esto por las bajas temperaturas que hacen que muchas veces los desperdicios orgánicos e inorgánicos permanezcan congelados al menos gran parte del año, evitando así su descomposición.

La composición de los residuos es tan diversa que los desechos afectan de múltiples formas al medio ambiente; desde material fecal hasta baterías, lo que genera contaminación importante sobre el suelo, el subsuelo y las fuentes de agua. Estas fuentes contaminantes también afectan directamente a la fauna local, cambiando sus hábitos alimenticios, envenenando a algunas de ellas directa e indirectamente y muchas veces también destruyendo los hábitats naturales y las fuentes de agua.

Algo similar a lo anterior ocurre con la instalación de carpas o tiendas de campaña (-334), que, a diferencia de la instalación de un camping como infraestructura, no se tienen los cuidados adecuados son los factores ambientales evaluados; por otro lado, los baños improvisados (-296) tienen un comportamiento móvil y de poco cuidado lo que se complementa con los pozos negros (-195) aumentando la contaminación cruzada y la presencia bacteriana especialmente en las fuentes de agua líquida.

En el otro lado de la moneda vemos que las actividades de desplazamiento en general son más inocuas, con excepción la carga puntual que generan y su afectación sobre la flora local, así como algunos efectos sobre la nieve y los suelos; se debe considerar que cada actividad fue evaluada por si sola y en su capacidad de generar impactos, esto es importante pues si el desplazamiento a píe o en esquís de travesía conlleva el abandono de desperdicios sólidos o la introducción de especies exóticas (garrapatas, por ejemplo), entonces la actividad deja automáticamente de ser inofensiva generando impactos significativos.

Lógica Vertical: Respecto de los factores ambientales evaluados, es el Agua el que se ve con mayor daño ambiental producido por la práctica deportiva de alta montaña, destacando la calidad (-212), principalmente afectada por la presencia de baños improvisados y por la presencia de desperdicios; aguas superficiales también se ve afectada por las mismas actividades (-160) así como nieves y hielos (-154) al cual se le suma la actividad de instalación de carpas, todas asociadas al campamento. y nieves también se ven afectados por la actividad.

Por otro lado, los Suelos (-178) es un factor ampliamente afectado, destacando el efecto que tienen los baños improvisados, pero sufriendo la afectación por todas las actividades evaluadas, situación similar a la de los Animales Terrestres (-140) quienes ven modificadas sus costumbres por la sola presencia del ser humano, así como por la instalación de campamentos.

Finalmente, y para ser justos, se debe dejar espacio para el componente ambiental «Empleo», pues es éste el que recibe la calificación positiva mayor (Ponderación de +33), esto se debe a que, planificado o no, el turismo deportivo es una actividad principalmente económica e intensiva en mano de obra y como tal produce trabajo remunerado tanto para personal foráneo como para la comunidad local.

\section{Discusión}

De lo mostrado anteriormente se desprende que una de las principales labores al momento de planificar actividades deportivas en espacios de alta montaña es la gestión adecuada de los residuos sólidos tanto para evitar la aparición 
de nuevos microbasurales como para reparar los sectores que ya se encuentran contaminados, esto incluye a aquellas actividades propias del deporte no competitivo como el ascenso a grandes cumbres, como también la necesidad de desarrollar investigaciones que expliquen los impactos de otro tipo de eventos, como, por ejemplo, las carreras de trail running (Urbaneja \& Farías, 2018) o de esquí de montaña.

Queda decir que, a pesar de que la percepción es de una actividad inofensiva, la verdad es que, al final del día, los sectores de práctica de la alta montaña están altamente impactados por las actividades recreativas; existen varios ejemplos de estos efectos antes mencionados, cada uno con diferentes niveles de impacto como se vio en el estudio; uno de ellos es la presencia de heces humanas, que se encuentran en cuencas de montaña, donde las bacterias, protozoos $\mathrm{y}$ virus tienen la capacidad de causar enfermedades como hepatitis $A$, gastroenteritis y enteroparasitosis a través de agentes patógenos como la Salmonella y otros lo que afectaría a los deportistas de manera inmediata.

Los elementos como baterías son capaces de contaminar importantes cuerpos de agua que, probablemente puedan ser purificados una vez el agua llegue a las plantas de tratamiento, sin embargo, las comunidades de montaña, arrieros, indígenas y otros, consumen el líquido elemento antes de pasar por estos lugares.

La compactación de suelos, formación de huellas y cárcavas, desaparición de la flora y fauna, fracción mecánica de rocas y otros son también elementos que han sido revisados y que, a la fecha, no están siendo abordados por ninguna organización nacional en Chile.

Importante destacar, por otro lado, los esfuerzos realizador por organismos como la Union Internationale des Associations d'Alpinisme (UIAA) quienes han desarrollado declaraciones internacionales así como también objetivos y directrices medioambientales (UIAA, 2002) las cuales deben ser revisadas, adaptadas, incorporadas y promocionadas por los clubes de montañismo adscritos a las diversas federaciones deportivas de, así como lo ha hecho la Federación Española de Deportes de Montaña y Escalada (FEDME) al desarrollar su propio procedimiento para el control medioambiental de eventos deportivos no competitivos de «alpinismo» (FEDME, 2002), así como la Guía de buenas prácticas para el desarrollo de carreras por montaña en espacios naturales protegidos (EUROPARC, 2016); tarea pendiente para la Federación de Andinismo de Chile.

Por otra parte, es recomendable que los cursos de capacitación formales que tomen guías, instructores y profesores que se dediquen al fomento de estas prácticas incluyan contenidos que permitan valorizar el medio ambiente de montaña para luego entregar herramientas y técnicas a aplicar para su conservación.

\section{Conclusiones}

El estudio ha revelado dos fenómenos que combinados pueden ser muy perjudiciales: el primero de ellos es la evidente existencia de efectos indeseados que nacen a partir de la práctica de las actividades deportivas en alta montaña y el segundo es el desconocimiento de los mismos por parte de las autoridades, empresarios turísticos y organizaciones de- portivas.

Las zonas de alta montaña se consideran localizaciones apropiadas para las actividades recreativas y turísticas de un público especializado y se vienen utilizando como tales desde hace mucho tiempo; el territorio montañoso es en sí especial, aquí se conjugan todos los factores que clásicamente se han introducido en el análisis geográfico pero con una realidad diferente: en la alta montaña se dan geoformas diferentes, el clima, la humedad, la oscilación térmica han terminado por formar suelos que se comportan de manera muy dinámica, una biota altamente adaptada y especializada, espacios poco antropizados y «acostumbrados» sólo a la trashumancia muy esporádica y adaptada a zonas de productividad cambiante han convertido a la alta montaña en un lugar «extraño» y distante para muchos que atrae cada vez a más deportistas.

Ahora bien, es importante mencionar que a nivel académico, en nuestro país, no se han hecho estudios sistemáticos acerca de los efectos negativos de la actividad deportiva o recreativa en zonas de montaña, lo que no permite tomar decisiones acertadas ni conocer realmente que está pasando con los residuos humanos y su incidencia sobre el medio ambiente y menos incentivar las buenas prácticas y las técnicas de minimización de impactos por parte de los deportistas de alta montaña con adaptaciones a la realidad local.

Lo anterior es clave ¿cómo planificar si no conocemos el problema? Se evidencia la necesidad de fortalecer tanto la investigación científica sobre los efectos de la actividad humana en zonas de altura, como también la difusión de sus resultados hacia los tomadores de decisiones públicas y, por sobre todo, hacia los clubes y federaciones de montaña, pues son estas personas quienes tendrán la capacidad de resguardar aquellos espacios que no pueden ser protegidos por los sistemas tradicionales de conservación de la biodiversidad. Por otro lado, aquellas instituciones formadoras de guías e instructores tendrán la responsabilidad de contar con procesos formativos y la creación o adaptación de buenas prácticas propias para cada realidad territorial.

\section{Referencias}

Barros, A., \& Pickering, C. (2015). Impacts of experimental trampling by hikers and pack animals on a high-altitude alpine sedge meadow in the Andes. Plant Ecology \& Divertisty, VIII(2), 265-276.

Barros, A., Monz, C., \& Pickering, C. (2015). Is tourism damaging ecosystems in the Andes? Current knowledge and an agenda for future research. $A M B I O, X L I V(2), 82-$ 98.

Börgel, R., Romero, H., \& Vio, D. (1983). Fundamentos Geográficos del Territorio Nacional. Santiago de Chile: Instituto Geográfico Militar.

Callizo, J. (1991). Aproximación a la Geografía del Turismo. Madrid, España: Síntesis.

Cánepa, L.,\& Encabo, M. (2013). Montañismo en Áreas Naturales Protegidas. Trekking y ascenso en la Ruta Noroeste del Volcán Tromen. $X$ Congreso Argentino y $\mathrm{V}$ Latinoamericano de Educación Física y Ciencias. Departamento de Educación Física, Facultad de Humanida- 
des y Ciencias de la Educación (UNLP), La Plata.

CONAF. (2018). Corporación Nacional Forestal. Recuperado de: http://www.conaf.cl/parques-nacionales/ visitanos/estadisticas-de-visitacion/

EUROPARC. (2016). Guía de buenas prácticas para el desarrollo de carreras por montaña en espacios naturales protegidos. Madrid: Fundación Fernando González Bernáldez.

FAO. (2012). Diagnístico Nacional de Montaña: Fortalecimiento de la gestión participativa para el desarrollo sostenible de los Andes. Santiago de Chile: Organización de las Naciones Unidas para la Alimentación y la Agricultura.

Farías, E., \& Sallent, O. (2009). El impacto ambiental de las actividades físico-deportivas en el medio natural: el caso de la práctica del «Mountain Bike» o bicicleta todo terreno. Retos. Nuevas tendencias en Educación Física, Deporte y Recreación(16), 31-35.

FEDME. (2002). Protocolo Medioambiental de la FEDME. Recuperado de: http://www.fedme.es/ index.php?mmod=static Content\&IDf=295

Funnel, D., \& Parish, R. (2001). Mountain environments and communities. Nueva York: Routledge.

Gabriel, A., Jordan, R., Millar, H., Pérez, T., \& Urtubia, E. (2006). Los 6000's de Chile. Santiago de Chile: Vertical S.A.

García, L. (2004). Aplicación del Análisis Multicriterio en la Evaluación de Impactos Ambientales. Barcelona: Universidad Politécnica de Cataluña.

Gill, A., \& Williams, P. (1994). Managing growth in mountain tourism communities. Tourism Management, XV(3), 212220.

Global Environmental Facility. (2002). High Priorities: GEF's contribution to conserving and sustaining mountain ecosystems. Washington DC: Global Environmental Facility.

Guillén, R., \& Peñarrubia, C. (2013). Incorporación de contenidos de Actividades en el Medio Natural mediante la investigación-acción colaborativa. Retos. Nuevas tendencias en Educación Física, Deporte y Recreación(23), 23-28.

Gutierrez, F., Larrain, P., Molina, I., \& Rivera, C. (1986). Geografía Región Metropolitana de Santiago. Santiago de Chile: Instituto Geográfico Militar.

INN. (2005). Turismo Aventura: Alta Montaña. Santiago de Chile: Instituto Nacional de Normalización.

Körner, C. (2000). The alpine life zone under global change. Gayana Botánica, LVII(1), 1-17.

Leopold, L., Clarke, F., Hanshaw, B., \& Balsley, J. (1971). A Procedure for Evaluating Environmental Impact. Geological Survey Circular(645). Washington.

Ley Nº19.300. Aprueba Ley Sobre Bases Generales Del MedioAmbiente. Publicada en Diario Oficial de la República de Chile, Santiago, Chile, 9 de marzo de 1994

López, S., Manerio, R., Moral, J., Amatria, M., DIez, P., Barcala, R., \& Abelairas, C. (2019). Los riesgos en la práctica de actividades de naturaleza. La accidentabilidad en las prácticas deportivas y medidas preventivas. Retos. Nuevas tendencias en Educación Física, Derporte y Recreación(36), 513-519.

Morilla, P., Rebollo, S., Baena, A., Miranda, M., \& Martínez,
M. (2013). Análisis del perfil sociodemográfico, deportivo y psicológico en una práctica de escalada deportiva de estudiantes universitarios. Retos. Nuevas tendencias en Educación Física, Deporte y Recreación(24), 9-15.

Mutana, S., \& Mukwada, G. (2018). Mountain-route tourism and sustainability. A discourse analysis of literature and possible future research. Journal of Outdoor Recreation and Tourism(24), 59-65.

Niedermeier, M., Weisleitner, A., Lamm, C., Ledochowski, L., Frühauf, A., Wille, M., . . Kopp, M. (2017). Is decision making in hypoxia affected by pre-acclimatisation? A randomized controlled trial. Physiology and Behavior(173), 236-242.

Olivares, M. S. (2002). Los efectos de los instrumentos reguladores sobre un grupo tradicional y minoritario. Caso de estudio: Los Arrieros de la comuna de Lo Barnechea. Tesis para optar al grado de Magister en Asentamientos Humanos y Medio Ambiente. Santiago de Chile: Pontificia Universidad Católica: Instituto de Estudios Urbanos.

Rebolledo, P., \& Fica, R. (2010). La formación de guías de turismo de montaña y alta montaña: el caso chileno. Gestión Turística(14), 83-95.

Saz, M., \& Carús, L. (2008). La sostenibilidad del turismo recreativo de alta montaña. Cuadernos de Desarrollo Rural, V(60), 11-36.

Stankey, G., \& Manning, R. (1986). Carrying Capacity of Recreation Settings. ALiterature Review: The President's Commission on Americans Outdoors. Recuperado de: http://winapps.umt.edu/winapps/media2/leopold/pubs/ 166.pdf

Sundriyal, S., Shridhar, V., Madhwal, S., Pandey, K., \& Sharma, V. (2018). Impacts of tourism development on the physical environment of Mussoorie, a hill station in the lower Himalayan range of India. Journal of Mountain Science, XV(10), 2276-2291.

Teillier, S., Marticorena, A., \& Niemeyer, H. (2011). Flora Andina de Santiago: Guía para la identificación de las especies de las cuencas del Maipo y del Mapocho. Santiago: Editorial Universitaria

UIAA. (1997). Objetivos y Directrices Medioambientales de la UIAA. Kranjska Gora: Union Internationale Des Associations D’Alpinisme.

UIAA. (2002). UIAA Environmental Objectives and Guidelines. Bern: Union Internationale des Associations d'Alpinismo.

UNEP. (2007). Turismo y Montaña: Guía práctica para gestionar los impactos sociales y medioambientales del turismo de montaña. París: Programa de las Naciones Unidas para el Medio Ambiente.

Urbaneja, J., \& Farías, E. (2018). El trail running (carreras de o por montaña) en España. Inicios, evolución y (actual) estado de la situación. Retos. Nuevas tendencias en Educación Física, Deporte y Recreación(33), 123-128. 